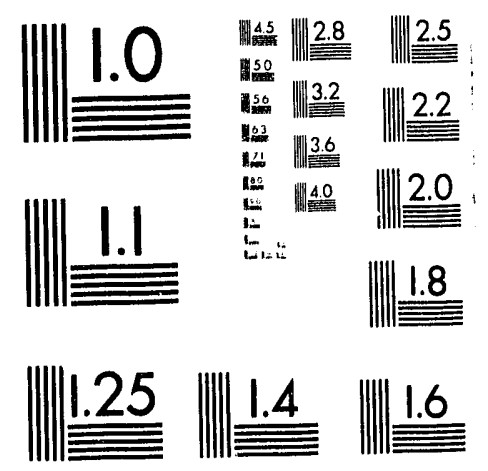



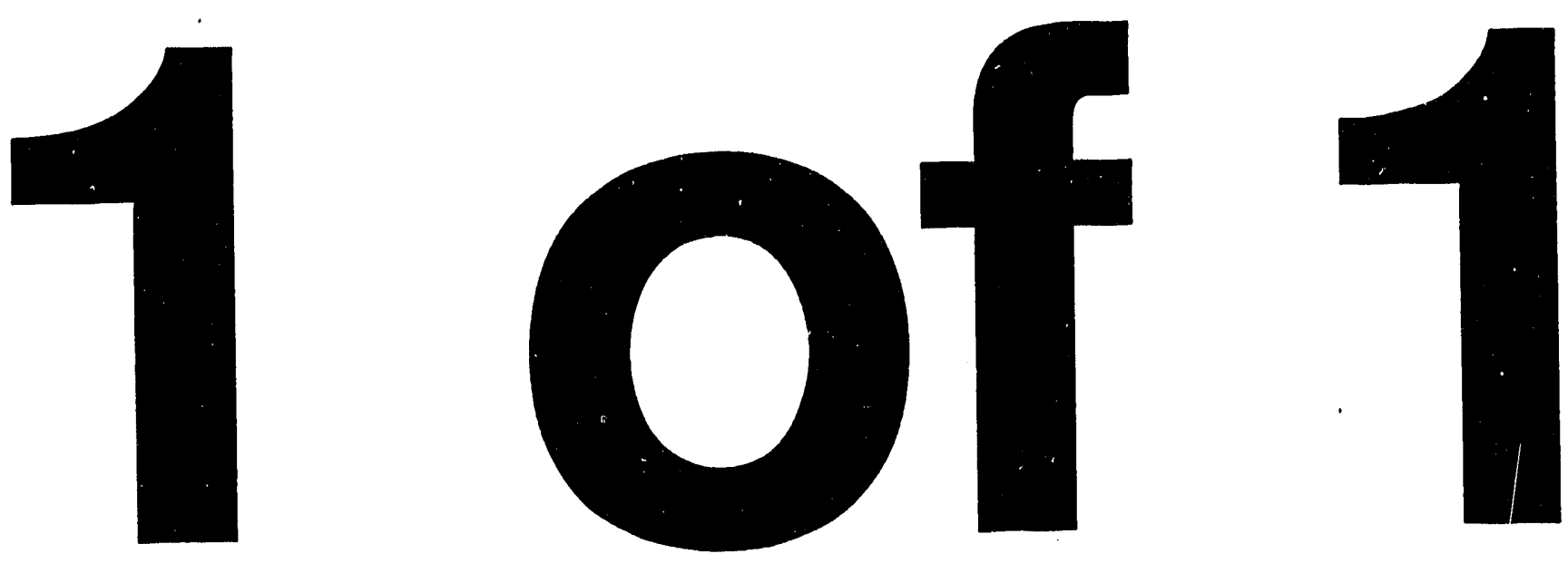


\title{
Real-Time Seam Tracking for Rocket Thrust Chamber Manufacturingi
}

Dan J. Schmitt and Jim L. Novak Sandia National Laboratories Albuquerque, NM 87185-5800

\author{
Gregory P. Starr \\ The University of New Mexico \\ Albuquerque, NM 87131
}

\author{
John E. Maslakowski \\ Rocketdyne Division, Rockwell International Corporation \\ Canoga Park, CA 91303
}

\begin{abstract}
A sensor-based control approach for real-time seam tracking of rocket thrust chamber as inblies has been developed to enable automation $0 i^{-}$a braze paste dispensing process. This approach utilizes a non-contact Multi-Axis Seam Tracking (MAST) sensor to track the seams. The MAST sensor measures capacitance variations between the sensor and the workpiece and produces four varying voltages which are read directly into the robot controller. A PID control algorithm which runs at the application program level has been designed based upon a simple dynamic model of the combined robot and sensor plant. The control algorithm acts on the incoming sensor signals in real-time to guide the robot motion along the seam path. Experiments demonstrate that seams can be tracked at $100 \mathrm{~mm} / \mathrm{sec}$ within the accuracy required for braze paste dispensing.
\end{abstract}

\section{INTRODUCTION}

Large classes of manufacturing processes require the ability to track gaps or seams between mating parts. Automation of these processes is often further challenged when small lot manufacturing is involved. Small lots often preclude the use of precision fixtures to precisely locate these features for the automation equipment. Sandia National Laboratories and the Rocketdyne Division of Rockwell International have entered into a cooperative research and development agreement (CRADA) to address these issues for the manufacturing of rocket engine thrust chambers.

Rocketdyne manufactures rocket engines for Delta and Atlas main rocket boosters $[1,2]$. The thrust chamber portion of the engines consists of hundreds of tubes which are brazed together to form a solid heat exchanger assembly. Rocketdyne currently fabricates these assemblies by fixturing the tubes together and manually dispensing nickel powder and palladium-silver braze paste into each seam between the butted tubes. The entire assembly is then placed in a gas fired furnace where the braze paste melts producing the solid structure.

Rocketdyne and Sandia are currently pursuing an automated approach for dispensing the braze paste. The goal in automating this process is to reduce the amount of labor hours and excess material required. The current process is time consuming because hundreds of seams must be processed on each assembly. The tube diameters change continuously down the length of the thrust chamber requiring varying amounts of paste along the seam. This is difficult to control manually and often results in excess application of paste.

The automated system will combine the precise motion control of a robot with precision paste dispensing equipment. The challenge in this effort is for the robot to locate and then track the seams at a constant speed. Since this is a small lot manufacturing process, and because the pre-brazed assembly has some flexibility, precision fixturing of the part is impractical. In addition, since each assembly has hundreds of tubes, the tolerances of these tubes accumulate resulting in unique scam locations on cach assembly.

This paper will describe a sensor-based control approach for locating and tracking scams in real-time. A noncontact Multi-Axis Seam Tracking (MAST) sensor system will be discussed. A PID control algorithm has been designed based on a simple dynamic model of the

${ }^{1}$ This work was performed at Sandia National Laboratories and supported by the U.S. Department of Energy under contract DE-ACO4-76DPPOO789.

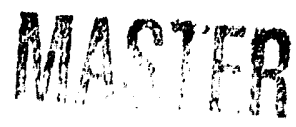

DISTAIBUTIUN OF THIS DOCUMENT IS UNLIMITEL

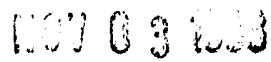


combined robot and sensor plant. This control algorithm has been implemented to conduct experiments in reallime scam tracking accuracy.

\section{SYSTEM COMPONENTS}

\section{a. Capacitive Sensor}

A unique, non-contact capacitive sensor is being used to locate and track the tube seams in real-time. The MultiAxis Seam Tracking (MAST) sensor has been designed specifically for this application [1,3] based on a capacitive sensing technology developed at Sandia National Laboratories [4]. The MAST sensor is fabricated from an inexpensive five layer printed circuit board and is approximately $15 \mathrm{~cm}$ long and $2.5 \mathrm{~cm}$ wide. A diagram of the sensor is shown in Figure 1. The sensor consists of four capacitor electrodes which are arranged to provide tracking information in the $\Delta y$ and $\Delta z$ directions, and the $\Delta p$ orientation (rotation about $y$ ). Signals from the sensor are carried by a ribbon connector to signal conditioning electronics. The output from the electronics is four varying voltages, one associated with each adjacent electrode pair. These voltage values can be read into the robot controller for position control.

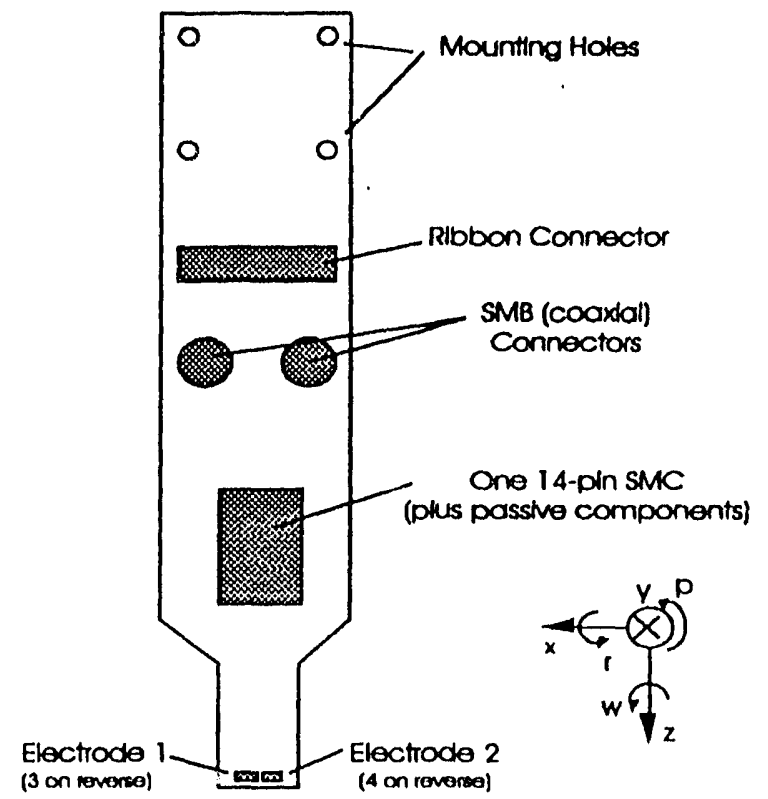

Figure 1. Diagram of the Multi-Axis Seam Tracking (MAST) sensor.

The MAST sensor generates four electric ficlds which are perturbed by the workpiece causing a variation in capacitance. These ficlds are shown in two vicws in Figure 2. Figure 2 a shows a top view of the MAST sensor positioned directly over the seam between two butted tubes. The ficlds associated with electrode pairs 1-2 and 3-4 extend primarily outward and are referred to as "side-looking." The difference between the two corresponding voltages is proportional to cross-seam (y) displacement.
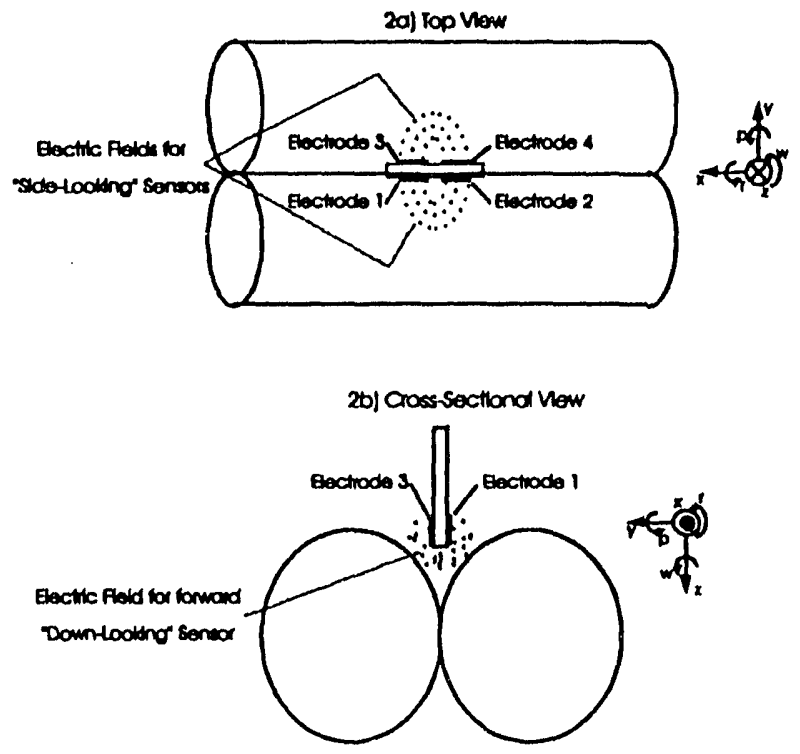

Figure 2. The MAST sensor principle of operation.

a) Top view illustrating the "side-looking" sensing fields.

b) Side view illustrating the "down-looking" fields.

Figure $2 b$ shows a side view of the MAST sensor directly over a seam. The fields between electrode pairs 1-3 and $2-4$ (into the page) extend downward and are referred to as "down-looking." The sum of the corresponding voltages is proportional to displacement above the seam (z). Finally, the difference of the $1-3$ and $2-4$ voltages yields an output proportional to orientation about the cross-seam (y) axis.

\section{b. Robot and Controller}

The control experiments were conducted on a Fanuc S-700 Robot with an R-J controller. This controller contains a $16 \mathrm{MHz} 68020 \mathrm{CPU}$ with a 68881 floatingpoint coprocessor. Application software was written in Karel, a Pascal-like, proprietary language for the Fanuc controller. The code was developed off-line using Fanuc's Off-Line Programming Software (OLPC) and downloaded to the robot controller for execution. 


\section{c. Delta 'Tool Software Option}

A Delta Tool software lunction, provided as a Karel option, permitted the use of MAST sensor data for realtime seam tracking. The Delta Tool function allowed a predefined nominal path to be exccuted while calculating path corrections based on the sensor output. The Delta Tool function accepted positional corrections calculated by the user and applied these corrections in the tool frame at a user defined update rate. This application used Delta Tool at a $56 \mathrm{msec}(18 \mathrm{~Hz})$ update rate. This is slower than the minimum update rate to allow a sufficient time-slice for the application program to calculate the positional correction for the next Delta Tool update. About $10 \mathrm{msec}$ was required to read the sensor channels and calculate the next update. Fanuc had indicated that a $25 \mathrm{MHz}$ CPU board with a 68882 floating coprocessor would enable Delta Tool to be used at a $28 \mathrm{msec}$ update rate.

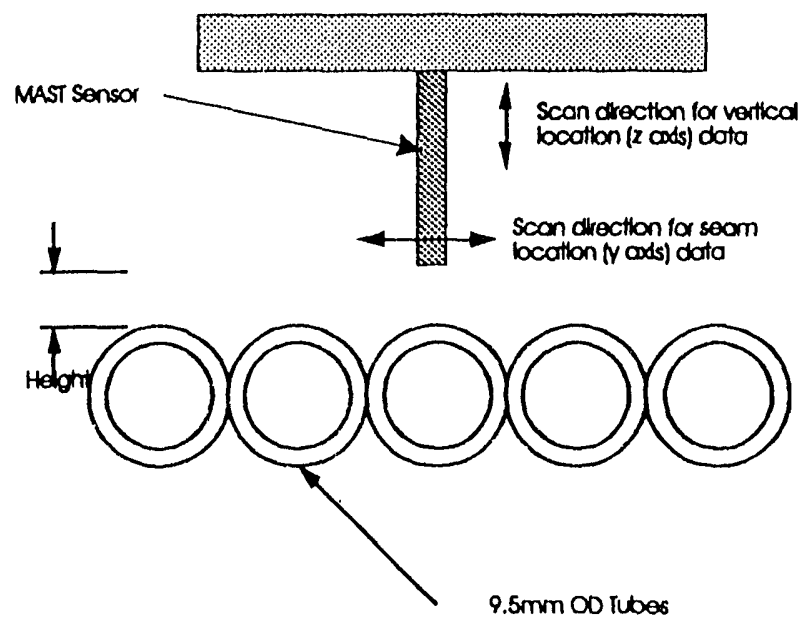

Figure 3. Flat tube assembly used to simulate the rocket thrust chamber surface.

\section{SENSOR CALIBRATION}

The incoming MAST sensor signals were calibrated with respect to the workpiece to be tracked. This was required so that these signals, in A/D counts, could be converted to absolute motions with respect to the workpiece. A flat bundle of $9.5 \mathrm{~mm}$ OD tubes, shown in Figure 3, was used to simulate the thrust chamber. Calibration data was obtained by scanning the MAST sensor across the tube bundle to obtain data for both the $y$ and $z$ axes. Figure 4 shows data collected for scans in the $y$ direction at various $z$ heights above the bundle surface. Plotted is the difference between the two side- looking scnsors, (1-2) minus (3-4). The plot shows a periodic signal which crosses 7 cro at the tube tops and the scam centers. The magnitude of the signal decreased as the $z$ scan height above the tube bundle increased, with a sensor dynamic range of $4 \mathrm{~mm}$. The slope of the line read positive when scanning across a seam and negative when scanning across a tube top providing a mechanism to distinguish between these two features.

In tracking the scams between adjacent tubes the sidelooking sensor is used first to position the tool directly over the scam. Assuming tracking is reasonably accurate, the sensor will remain in the vicinity of the scam near a positive-slope zero crossing in Figure 4. Since the slope of the sensor output is nearly constant near these zero crossings, a constant gain may be used to represent the $y$-axis behavior. For the experiments presented in this paper, the $y$-axis sensor gain was obtained at a height of $1 \mathrm{~mm}$ above the tube bundle surface. In the $z$ direction, the downward-looking sensor signal decreases monotonically as height $\mathrm{z}$ increases. Again, a constant calibration gain was obtained by approximating the slope of the $\mathrm{z}$ axis sensor response about the $1 \mathrm{~mm}$ height opcrating point.

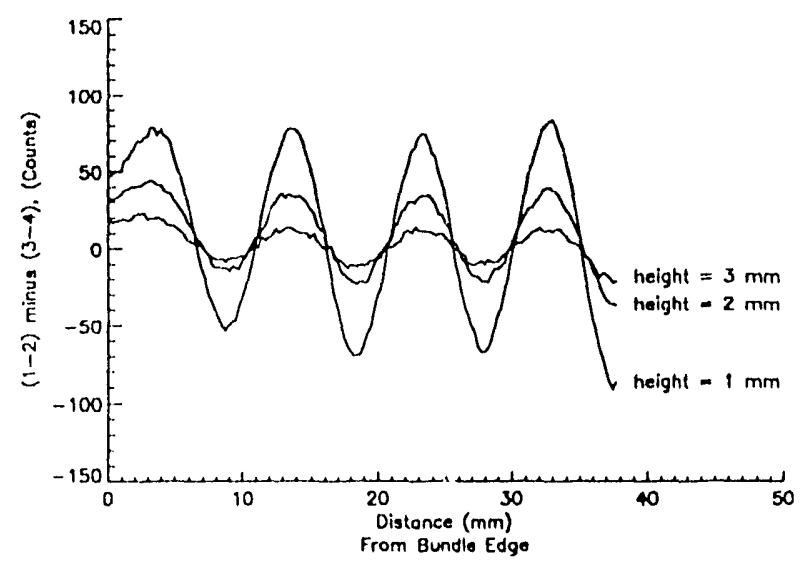

Figure 4. Y Axis calibration data at various heights above the tube bundle surface

\section{MODEL IDENTIFICATION}

To design a controller for this system, the response of the combined robot and sensor plant must first be characterized. Robot dynamics are in general nonlinear and lime-varying [5]. However, at the low link velocities and accelerations anticipated during seamtracking with this robot the nonlinear link dynamic effects are small. Also, the transmission gear reduction will effectively diminish the link dynamics as compared (1) actuator dynamics. Finally, the Fanuc position 
controller will reject friction torque disturbances. Under these conditions one can assume that incremental positioning of the robot and sensor can be functionally represented by a simple model obtained with the robot near the configuration of interest.

A suitable model was developed by characterizing the combined robot and sensor step response. The response of the (robot + sensor) plant to a $1 \mathrm{~mm}$ step input is shown in Figure 5. The sampling period was $56 \mathrm{msec}$, the Delta Tool update rate. This $1 \mathrm{~mm}$ step magnitude is expected to be a typical maximum correction during seam tracking. In Figure 5 the variable "MAST Sensor" is the difference between side-looking sensors. This variable represents the response of the (robot + sensor) plant to the step i! ?*. The variable "Disp Sensor" is an independent measure of the robot position using a displacement sensor. The difference between these two position measurements is due to analog filtering within the MAST sensor.

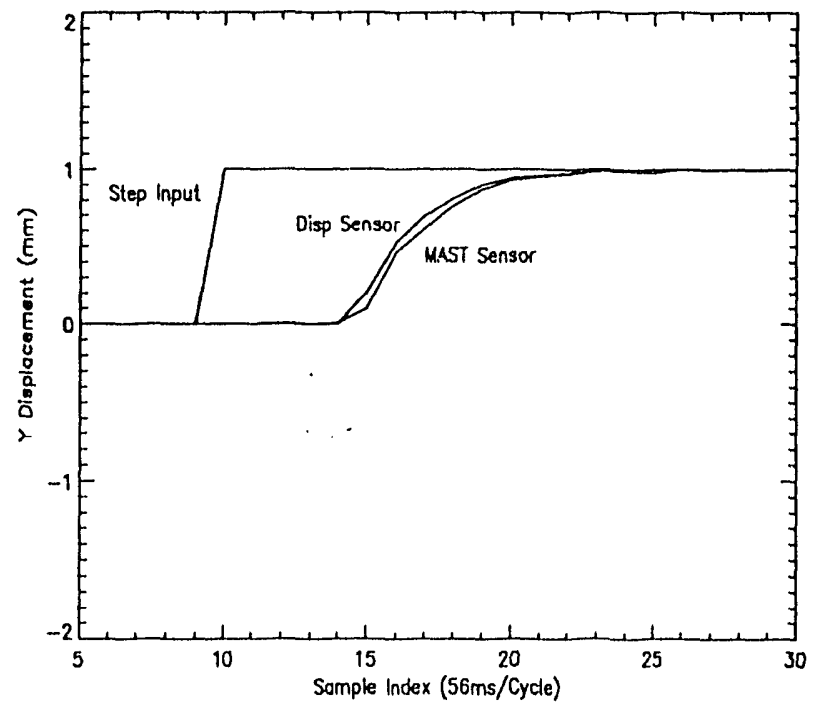

Figure 5. Step Response of (Robot + Sensor) Plant as measured by the MAST Sensor.

Since the observed step response was delayed but showed no overshoot, a first order model with five delays was fit to this response, with the steady-state gain set to one. The corresponding transfer function for the plant is

$$
G(z)=\frac{0.273 z^{-5}}{1-0.727 z^{-1}}
$$

Figure 6 compares the step response of this model with the measured step response.

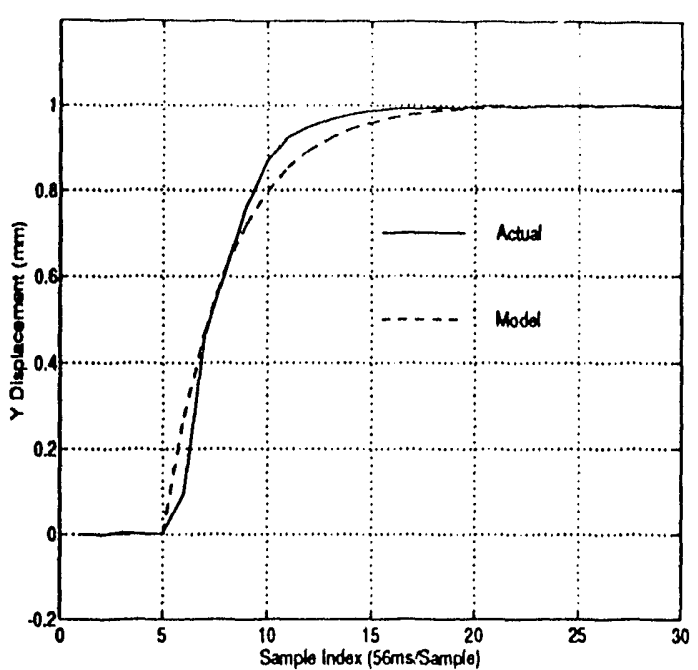

Figure 6. Actual and plant model step responses.

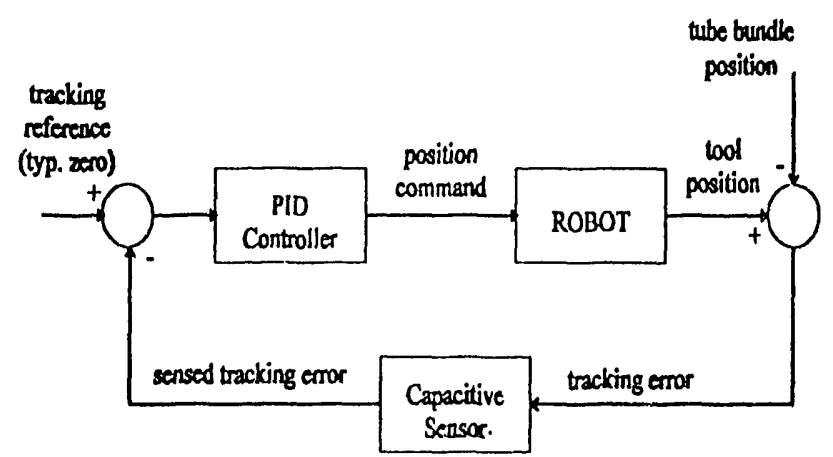

Figure 7. System block diagram.

\section{CONTROLLER DESIGN}

The cross-seam system block diagram is shown in Figure 7. The vertical regulation system is conceptually identical. The controller accepts sensed cross-seam error and generates position commands which are sent to the robot. A PID controller with transfer function

$$
D(z)=K_{p}+\frac{K_{d}(z-1)}{z}+\frac{K_{i} z}{z-1}=\frac{1.2-1.5 z^{-1}+0.5 z^{-2}}{1-z^{-1}}
$$

resulted in acceptable damping and rise time. A comparison of the actual step response of the system and that predicted by the model is shown in Figure 8 . The discrepancies are due primarily to inaccuracies in the robot and sensor models. 


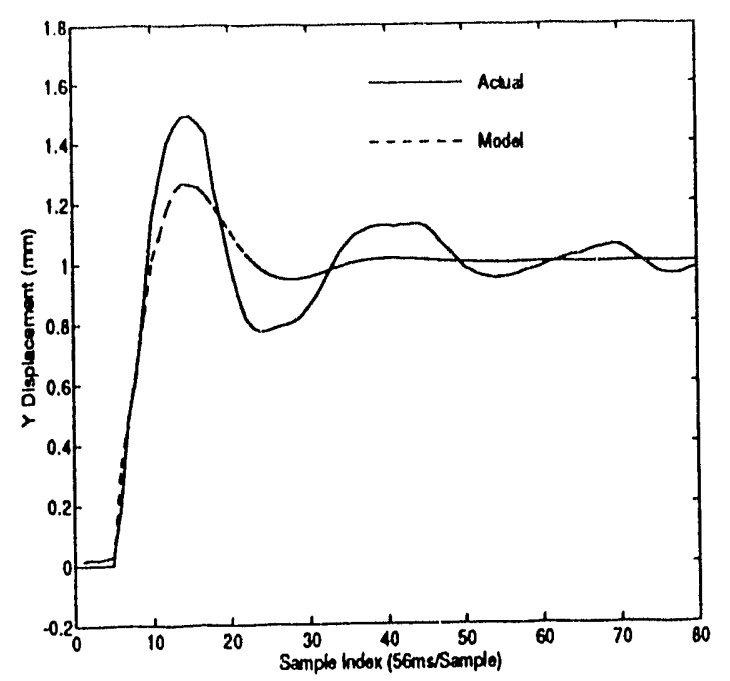

Figure 8. Controlled system model and actual step responses.

A root locus analysis was performed to examine the effects of $\pm 20 \%$ loop gain variation. Some variation will occur due to the change of sensor gain with displacement as shown in Figure 4. The root locus (Figure 9) shows the dominant poles change in damping ratio from about 0.55 to about 0.35 . The step responses corresponding to the two extremes of pole variation are shown in Figure 10.

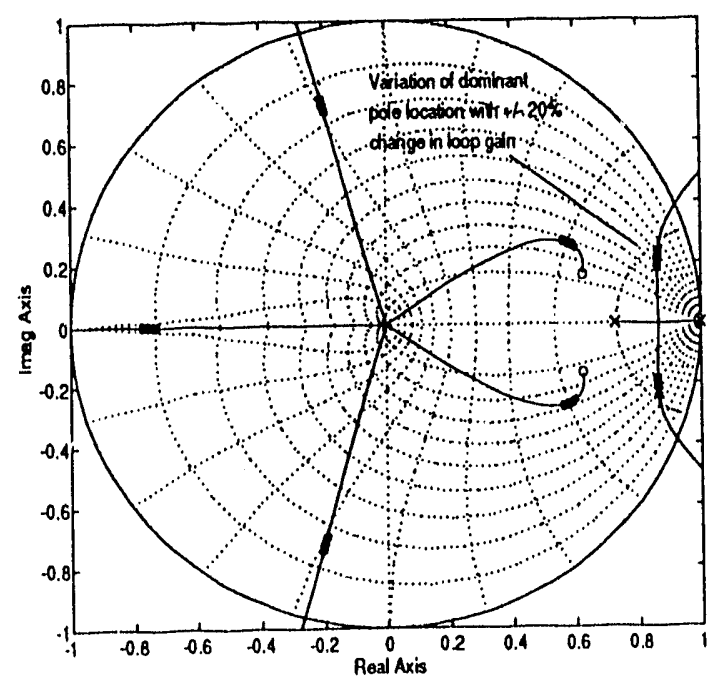

Figure 9. The effect on pole location of $\pm 20 \%$ variation in loop gain.

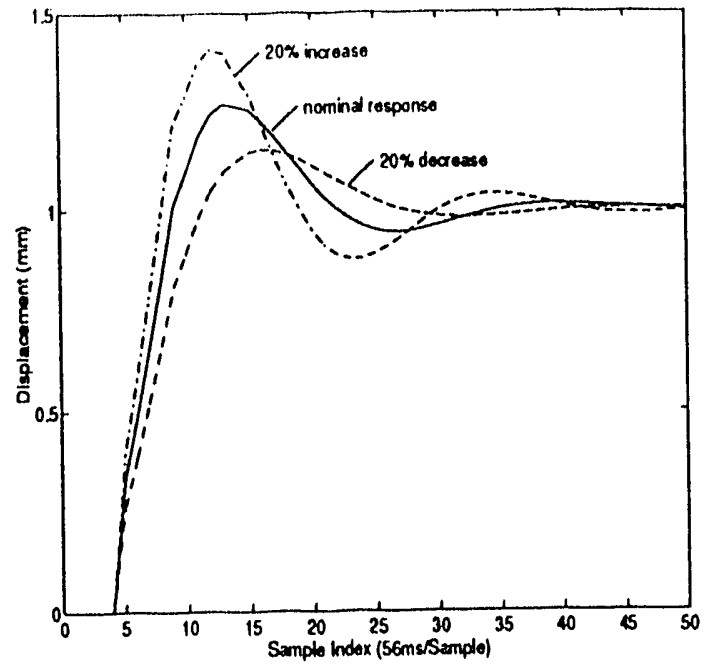

Figure 10. Step responses corresponding to $\pm 20 \%$ variation in loop gain.

\section{EXPERIMENTAL RESULTS}

Experiments were conducted to determine how accurately the sensor-based control system could track seam joints in real-time. The flat bundle of $9.5 \mathrm{~mm} O D$ tubes shown in Figure 3 was used to simulate the thrust chamber. The MAST sensor was used to track the seams in two dimensions. The side-looking sensors were used to make cross-seam corrections in the $y$ direction. The control set point in this case was an error of zero. The down-looking sensors were used to control the $\mathrm{z}$ height above the seam. The control set point in this case was a sensor reading corresponding to a fixed height of $1 \mathrm{~mm}$ above the top of the tube. The $\Delta p$ orientation (rotation about $y$ ) was not controlled in these experiments.

The strategy for tracking a seam was to use the sensor to find the center starting location of the seam before tracking started. In this way the tracking error was initially zero and a start-up transient was avoided. A nominal path was then constructed between this initial centered starting point and a point at the expected end of the seam. Misalignment of the tube bundle caused this nominal trajectory to be in error which provided a ramp disturbance to the tracking control system. The slope of this ramp disturbance was proportional to the tracking speed. The PID controller resulted in a Type I system, which had finitc stcady-state error to a ramp disturbance, proportional to the velocity of the ramp. Thus for a given maximum tracking error, tracking speed was 
dependent on the tube bundle misalignment. ^ Type II controller is being considered to climinate the steadystate tracking crror.

For the following experiment, the second path point on the flat tube bundle was defined at $x=760 \mathrm{~mm}, y=4.75$ $\mathrm{mm}, \mathrm{z}=4.75 \mathrm{~mm}$. This corresponded to a $y$ and $z$ crror of $1 / 2$ tube diameter. The seams were tracked at speeds of 50,100 and $200 \mathrm{~mm} / \mathrm{sec}$. The Delta Tool update rate was $56 \mathrm{msec}(18 \mathrm{~Hz})$. Figure 11 shows the RMS tracking error for the $y$ and $z$ directions for these various speeds. For the paste dispensing application, a combined tracking error of $0.5 \mathrm{~mm}$ is desired. Figure 11 shows that the seam can be tracked at $100 \mathrm{~mm} / \mathrm{sec}$ within a 0.4 $\mathrm{mm}$ combined error.

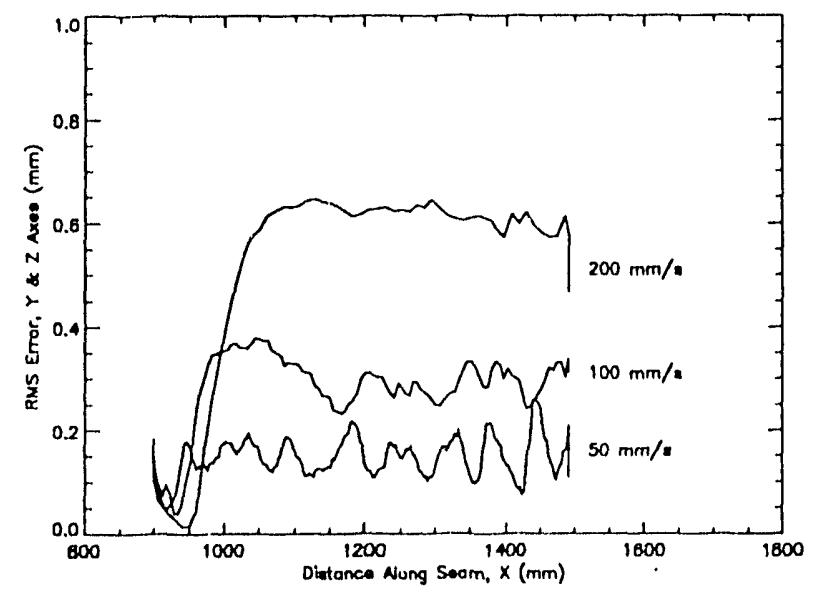

Figure 11. RMS tracking error versus distance along the sean for various tracking specds.

\section{SUMMARY}

This paper preser Ls a sensor-based control approach for real-time seam tracking on rocket thrust chamber assemblies. Four varying voltages output from the MAST sensor system are read directly into the Fanuc RJ controller through an A/D modulc. A PID control algorithm, designed based on a simple dynamic model of the combined robot and sensor plant, runs at the application program level. Using an $18 \mathrm{H} \%$ updatc rate, the MAST sensor data is used to control the robot motion along the seam. Experiments show that the seams can be tracked at $100 \mathrm{~mm} / \mathrm{sec}$ within a error of $(0.4 \mathrm{~mm}$.

\section{ACKNOWLEDCEMENT}

We would like to thank Sandia's Jon Bryan and Robert Waldschmidt for their efforts in fabricating the MAST scusors and signal conditioning electronics and Jim Akins for setting up the workcell and interfacing the electronics and computer hardware.

\section{REFERENCES}

1. J. Novak, D. Schmill, and J. Maslakowski, "Multiaxis seam tracking using a noncontact capacitive sensor," Proceedings of the SPIE Int. Symposium on Optical Tools for Manufacturing and Advanced Automation, Boston, MA, Sept. 1993.

2. D. Schmilt, J. Novak, J. Maslakowski, and A. Thiele, "Automating a braze paste dispensing operation using non-contact sensing," Proceedings of the Int. Robots and Vision Automation Conferencc, Detroit, MI, April 1993.

3. J.L. Novak, "Feature Tracking Impedance Sensor, "U.S. Patent Application \#08/042292, 1993.

4. J.L. Novak and J.J. Wiczer, "A high resolution capacitive imaging sensor for manufacturing applications, "Proceedings of the 1991 IEEE International Conference on Robotics and Automation, Sacramento, CA, 1991, pp.2071-2078.

5. J.J. Craig, Introduction to Robotics: Mechanics and Control, 2nd Edition, Addison-Wesley, 1989.

\section{DISCLAIMER}

This report was prepared as an account of work sponsored by an agency of the United States Neither the United States Gnvernment nor any agency thereof, nor any of their Government. Neither the bility prose or represents that its use would not infringe privately owned rights. Referprocess disclosed, or reprific commercial product, process, or service by trade name, trademark, manufacturer, or otherwise does not necessarily constitute or imply its endorsement, recommendation, or favoring by the United States Government or any agency thereof. The views and opinions of authors expressed herein do not necessarily state or reflect those of the United States Government or any agency thereof. 


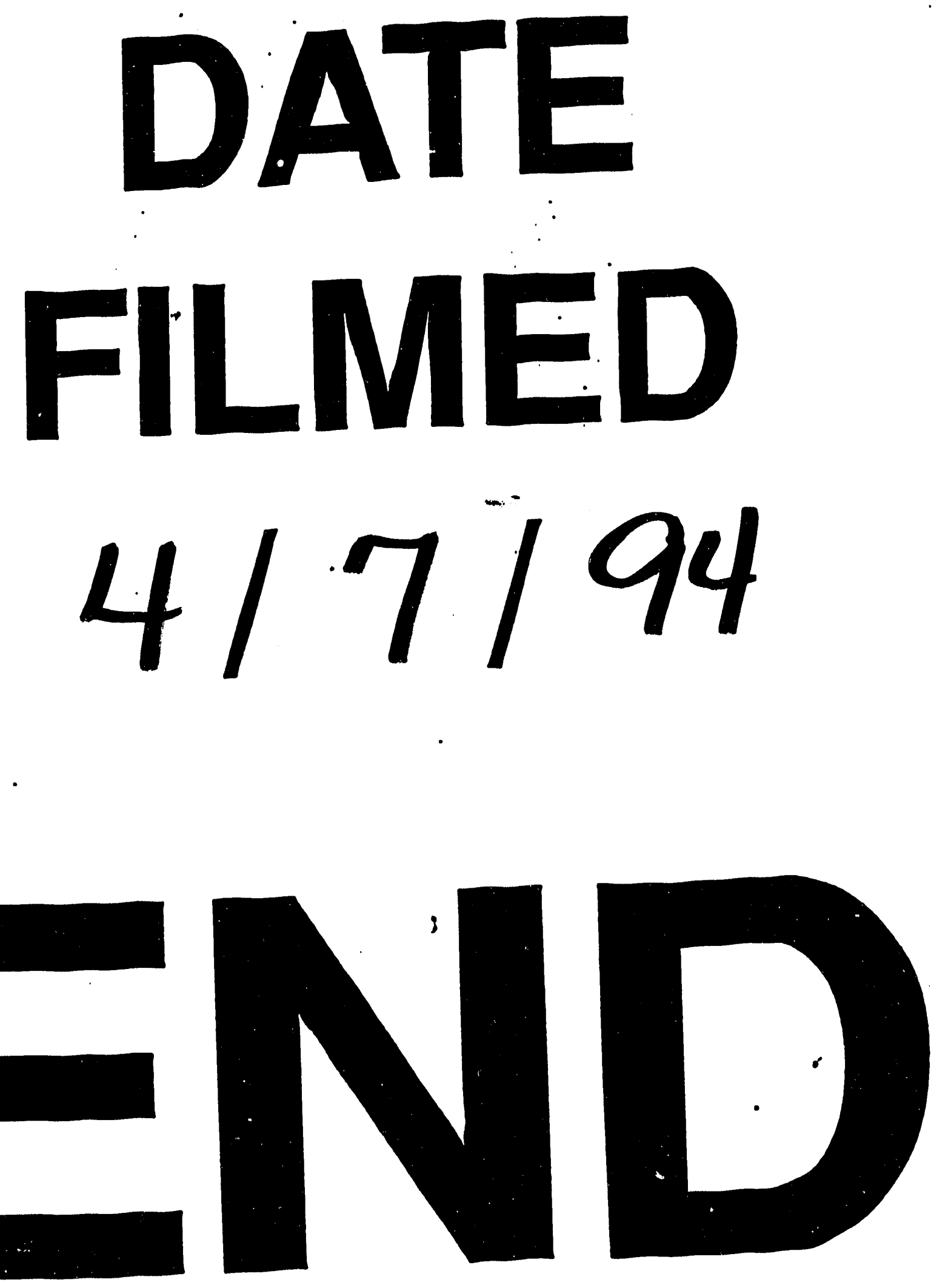


